\title{
DYNAMIC EQUILIBRIUM EXPLAINED USING THE COMPUTER
}

\author{
Hakan Sarıçayır \\ Musa Şahin \\ Musa Üce
}

\begin{abstract}
Since their introduction into schools, educators have tried to utilize computers in classes in order to make difficult topics more comprehensible. Chemistry educators, when faced with the task of teaching a topic that cannot be taught through experiments in a laboratory, resort to computers to help students visualize difficult concepts and processes. Computers offer viable means to teach dynamic equilibrium, a topic that has no laboratory manuals. Recently, chemistry educators have started to focus on how to use computer animations and simulations in the teaching of equilibrium.
\end{abstract}

KEYWORDS. Chemistry Education, Dynamic Equilibrium, Computer Animations.

\section{INTRODUCTION}

Most students fail to conceive the dynamic nature of chemical equilibrium. They think nothing more happens when the system reaches equilibrium. Many articles have documented learning difficulties, specific student misconceptions, and strategies for teaching chemical equilibrium. Some authors have offered ways of addressing these misconceptions (Wheeller and Kass 1978; Hackling and Garnett, 1985); others have written articles concerning student misconceptions about equilibrium and their diagnosis (Banerjee, 1991; Bergquist and Heikinen, 1990). The reasons for this failure are apparent. First, as it reported by Finely at al. (1990) chemical equilibrium is an abstract concept demanding the mastery of a large number of subordinate concepts. Even teachers don't fully understand the topic themselves (Linn, 1987; Tobin and Espinet, 1989). When they are asked to explain that equilibrium is dynamic, they are not able to do so. Thus, the teaching of dynamic equilibrium lends itself to the use of analogies to be explained and comprehended (Thiele and Tregust, 1994). Second, it is difficult to carry out an experiment to help students comprehend it. There is no laboratory manual for dynamic equilibrium in high school or university level. 
The teaching methods proposed to teach chemical equilibrium better (Treagust at all, 1999) include experiments, simulations (Huddle at all, 2000), and computer animations. For instance, Harrison and Buckly (2000) made a transparent simulation to explain dynamic equilibrium. They divided the students into two groups and gave them 24 small coins. The reaction scheme for a first order reversible reaction was shown to the class on an overhead projector transparency.

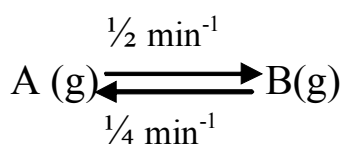

They put 24 students under A, and none under B. The students under A represented reactants, B represented products. Every minute half of the reactants were converted to products and $1 / 4$ of the products was converted back to reactants. A table of the kinetic data was also shown on the board. In this analogy, in the third minute, this simple simulation illustrates the concept of dynamic equilibrium.

Wilson (1998) did a similar simulation with 40 matches. He performed three activities. In the first activity, he explained dynamic equilibrium using the same mechanism as Harrison and we did. In the second activity, he again explained the dynamic equilibrium starting with a different number of matches but the same reaction rate. In the last activity, he used different reaction rates and temperatures to explain $\mathrm{K}$ changes with temperatures.

It was indicated that students had difficulty in understanding concepts at the particulate level and that it is the source of many student misconceptions (Williamson and Abraham, 1995). With the experiments and simulations performed in these two studies, it was not possible to reach the particulate level. Since the topic could not be grasped conceptually, we have designed this animation with the help of a computer program to make the dynamic equilibrium understood in the particulate level.

In this animation, we give a first order reversible reaction as Harrison and Buckley (2000) did. The students are told that constants (identified as rate constant) shown above and below the arrows are used to calculate the number of reactants going to products and vice versa at the end of each minute. A computer animation is accomplished to illustrate the actual reaction.

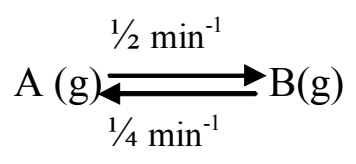


Table 1: The atom number-time table of first order reversible $\mathrm{A}(\mathrm{g}) \rightleftarrows \mathrm{B}(\mathrm{g})$ reaction for six minutes

\begin{tabular}{|c|c|c|}
\hline Time $/ \min$ & $\mathrm{A}(\mathrm{g})$ & $\mathrm{B}(\mathrm{g})$ \\
\hline 0 & 24 & 0 \\
\hline 1 & 12 & 12 \\
\hline 2 & 9 & 15 \\
\hline 3 & 8 & 16 \\
\hline 4 & 8 & 16 \\
\hline 5 & 8 & 16 \\
\hline 6 & 8 & 16 \\
\hline
\end{tabular}

On the computer screen there are two-sided boxes named A and B. In column A there are 24 atoms. Each atom is marked from 1 to 24 (Numbers are written on each atom from 1 to 24). On the right side of the box there are no atoms because the reaction has not started yet (Figure 1).

Figure 1: The states of the atoms before reaction

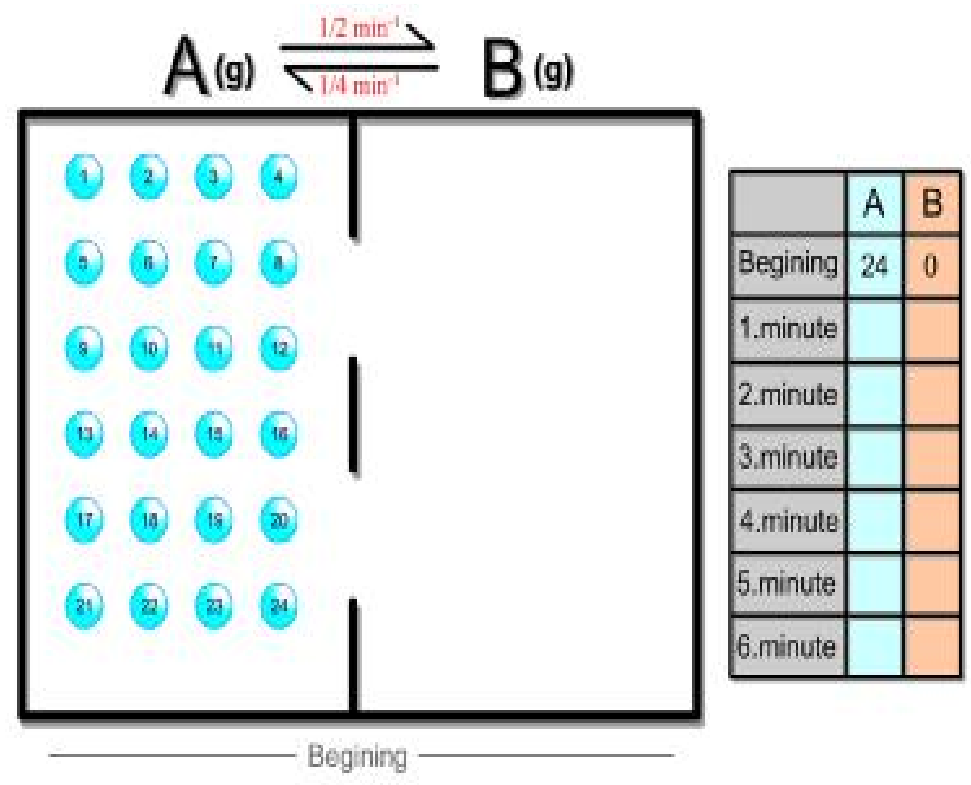

When the students press the first minute button, half of the atoms in the reactant side are produced to B $(24 / 2=12)$. During the first minute of chemical reactions occurring the color and size of the $\mathrm{B}$ atoms are changed in order to attract students' attention to these reactions. At the end of the first minute there are 12 atoms on either side (Figure 2). 
Figure 2: The states of the atoms in the first minute

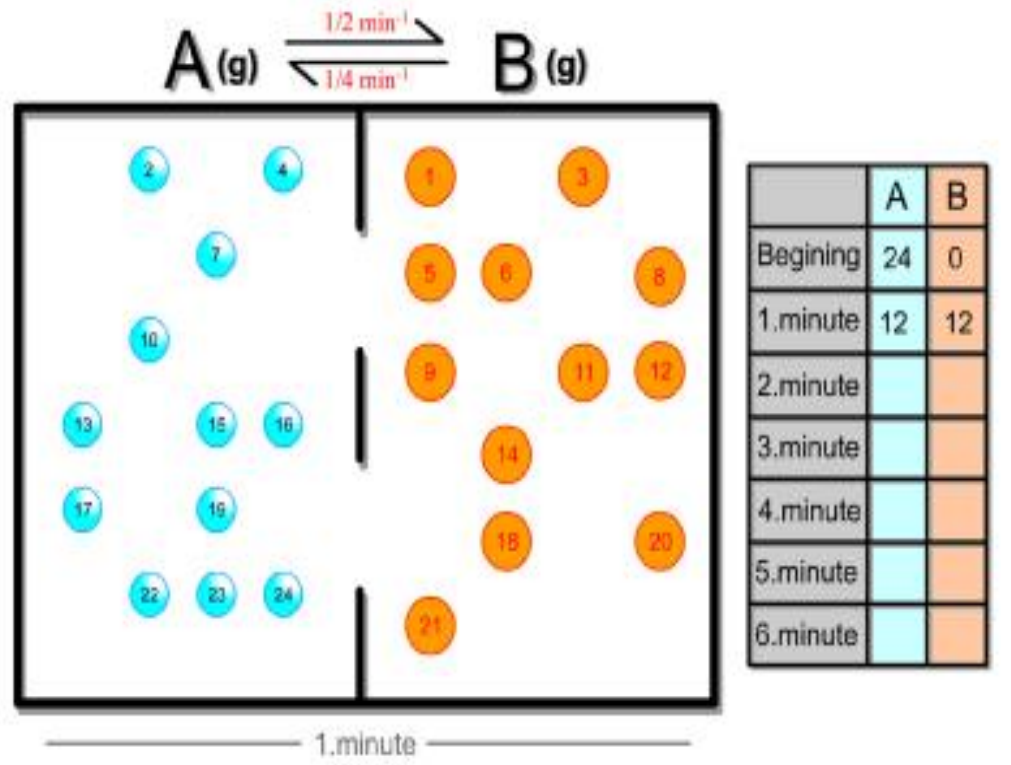

In the second minute, while half of the reactants produce $\mathrm{B}, 1 / 4$ of the products decompose to A. At the end of the second minute there are 9 atoms on the reactant side, 15 atoms on product side (Figure 3).

Figure 3: The states of the atoms in the second minute

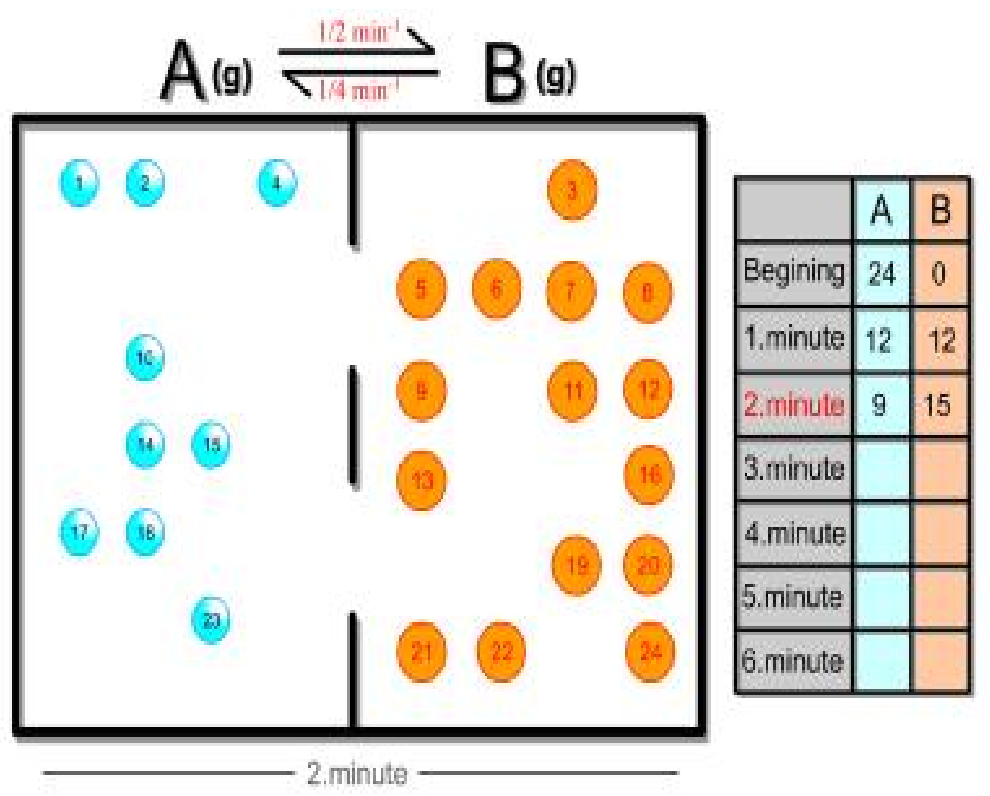

In the third minute, half of the reactants $(9 / 2=4,5)$ produce $\mathrm{B}$. While A produces $\mathrm{B}, 1 / 4$ of the $\mathrm{B}$ decomposes back to A. At the end of the third minute $4,5+3,75=8,2 \mathrm{~A}$ atoms and $15,8 \mathrm{~B}$ atoms are formed. We tell the students to round off 8,2 and 15,8 to 8 and 16 (Figure 4). 
Figure 4: The states of the atoms in the third minute

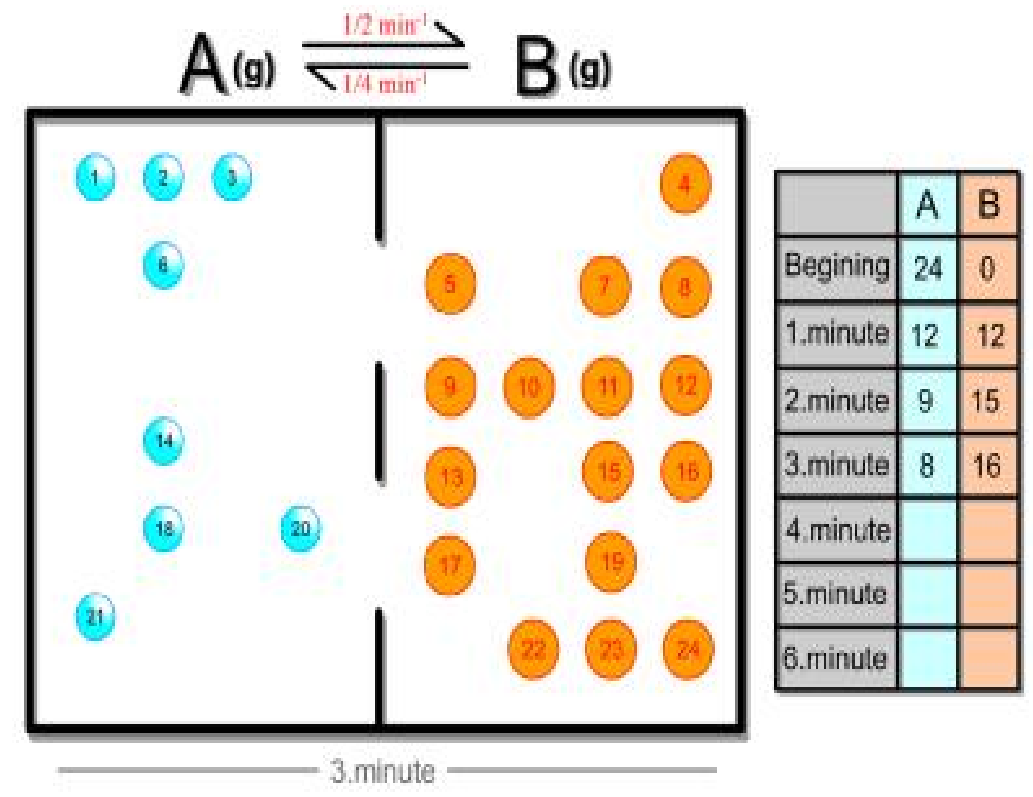

What happens during the fourth minute? Students see that the total numbers of the atoms on both the reactant and the product sides are constant (Figure 5).

Figure 5: The states of the atoms in the fourth minute

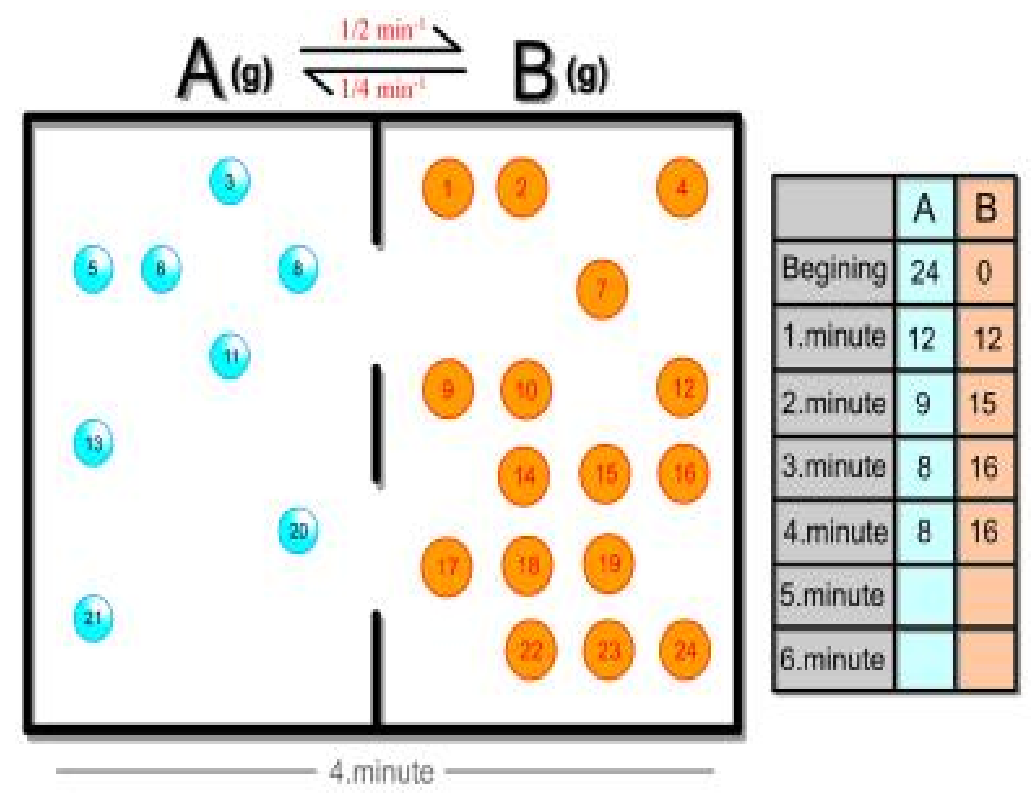

"We emphasize that when a system reaches equilibrium, concentrations of product and the reactant don't change but microscopic events still go on (because numbers are still changing but the total number of atoms doesn't change)" 
During the fifth and sixth minutes students are able to see this phenomenon clearly in this animation (Figure 6).

Figure 6: The states of the atoms in the fifth and sixth minutes
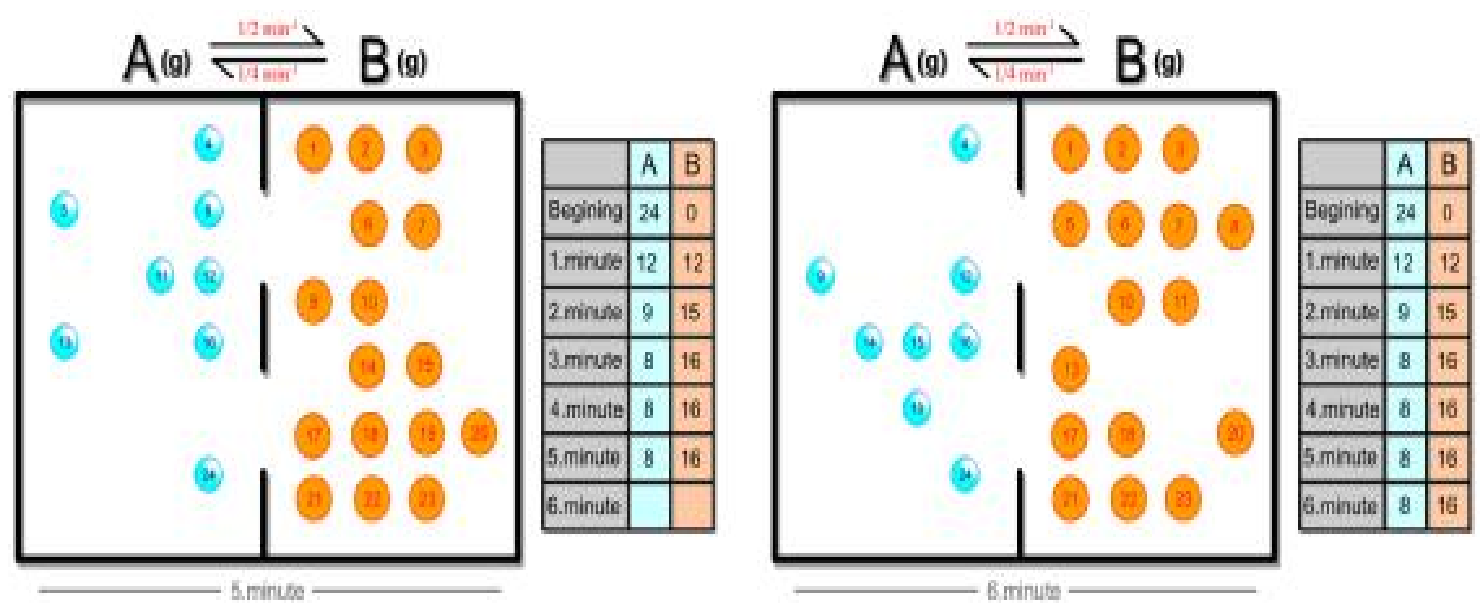

\section{CONCLUSION}

The study shows that computer animations might prove to be an invaluable means in the teaching of dynamic equilibrium. The animations used in this study, unlike those in similar ones, employ the presentation of dynamic equilibrium at molecular level, thus helping increase students' awareness of the subject and hinder formation of misconceptions. 


\section{REFERENCES}

Finely, F., Steward, J., Yarroch, W. (1982). Teachers' perceptions of important and difficult science content. Science Education, 66, 531-538

Wheeller, E.A., Kass, H. (1978). Students' misconceptions in chemical equilibrium. Science Education, 62(2): 223232

Hackling, M.W., Garnett, P.J. (1985). Misconceptions of chemical equilibrium "the associative framework". European Journal of Science. Education, 7, 205-211

Banerjee, A.C. (1991). Misconceptions of students and teachers in chemical equilibrium. International Journal of Science Education, 13, 487- 494

Bergquist, W., Heikinen, H. (1990). Student Ideas Regarding Chemical Equilibrium. Journal of Chemical Education, $67,1000-1003$

Treagust, D.F., Tyson. L., Bucat, R. (1999). The complexity of teaching and learning chemical equilibrium. Journal of Chemical Education, 76, 554-558

Huddle, P.A., White, W.M., Rogers, F. (2000). Simulations for teaching chemical equilibrium. Journal of Chemical Education, 77,920-925

Linn, M. (1987). Establishing a research base for science education challenges, trends and recommendations. Journal of Research in Science Teaching, 24, 191-216,

Tobin, K., Espinet, M. (1989). Impediments to change applications of coaching in high school science teaching. Journal of Research in Science Teaching, 26, 109-120

Thiele, R.B. Tregust, D.F. (1994). An interpretive examination of high-school chemistry teachers analogical explanations. Journal of Research In Science Teaching, 31, 227-242

Harrison, A., Buckley, D.P. (2000). Simulating dynamic equilibria. Journal of Chemical Education, 77, 1013-1014

Wilson, A.H. (1998). Equilibrium: a teaching/learning activity. Journal of Chemical Education, 75, 1176-1177

Williamson, M.V., Abraham, R.W. (1995). The effects of computer animation on the particulate mental models of college chemistry students' nature. Journal of .Research in Science Teaching, 32, 521-534 


\section{Hakan Sarıcavır}

Chemistry Department, Atatürk Faculty of Education

Marmara University, 81040 Kadıköy, Istanbul, Turkey

Tel:090 2163459090

Fax: 0902163388060

E-mail: hsaricayir@marmara.edu.tr

\section{$\underline{\text { Musa Sahin }}$}

Chemistry Department, Atatürk Faculty of Education

Marmara University, 81040 Kadıköy, Istanbul, Turkey

Tel:090 2163459090

Fax: 0902163388060

E-mail: musasahin@marmara.edu.tr

\section{Musa Üce}

Chemistry Department, Atatürk Faculty of Education

Marmara University, 81040 Kadıköy, Istanbul, Turkey

Tel:090 2163459090

Fax: 0902163388060

E-mail: musauce@marmara.edu.tr 